\title{
Mocarstwo słabych - o wartości starców w kulturze ludowej
}

\begin{abstract}
Kalniuk Tomasz, Mocarstwo stabych - o wartości starców w kulturze ludowej (The Power of the Weak: on Worthiness of Elders in Folk Culture). „Poznańskie Studia Slawistyczne" 5. Poznań 2013. Adam Mickiewicz University Press, pp. 131-141. ISBN 97883-232-2636-9. ISSN 2084-3011.

The folk culture from the turn of the $20^{\text {th }}$ century was founded on the mythical paradigm. Its specific feature was an opposition between the self and the other. It had ambivalent influence on those people and places which, due to actual or perceptual reasons, were placed on the margin of the mainstream of life. This includes, among others, the elders. On the one hand, they were treated by the community with reluctance, or even aggression, because of their decrepitude. On the other hand, they were respected as guards of traditions, and intermediaries with the supernatural, who possessed a portion of its potential.
\end{abstract}

Keywords: borders; elders; folk culture; myth; old age; others; sacrum; supernatural

Zagadnienia związane z kulturą ludową (także $\mathrm{w}$ aspekcie władzy i autorytetów), można rozważać w ramach kilku dyscyplin i za pomocą różnych metod. Biorąc pod uwagę złożoność tematu i wielość stanowisk wobec niego, a także zdając sobie sprawę z nieprecyzyjności terminu „kultura ludowa", uznaję go za nadrzędny przy opisywaniu interesujących mnie zjawisk. Kategoryzując to pojęcie historycznie, utożsamiam je ze sposobem życia na wsi (Brzezińska 2009: 159; Bylina 2002: 177-1781), mając na uwadze zwłaszcza realia odnoszące się do sytuacji na ziemiach polskich XIX i pierwszej połowy XX wieku. Najogólniejszy namysł nad kulturą prowadzi do wyodrębnienia dwóch porządków, mianowicie faktualnego i fenomenalnego (Zadrożyńska-Barącz 1968), co odpowiada daw-

${ }^{1}$ Autor zwraca uwagę na to, że choć nie wszyscy badacze utożsamiają kulturę ludową z chłopską, to w jego opinii, właśnie wśród chłopstwa cechy kultury ludowej zachowały się najdłużej (Bylina 1999: 5-6). 
nemu podziałowi na kulturę materialną i duchową (Staszczak 1987: 193194, 198-200). Obie sfery, faktualna i fenomenalna, znaczą swoją obecność $\mathrm{w}$ analizie zjawisk kulturowych, dlatego ścisły ich rozdział, także w przypadku badań nad życiem chłopstwa, wydaje się niemożliwy i schematyczny (Staszczak 1987: 194,199).

Określany mianem tradycyjnego, kształt kultury ludowej na ziemiach polskich z przełomu XIX i XX wieku to z jednej strony jej wielowymiarowa marginalizacja hamująca rozwój sfery techniczno-użytkowej (Myśliwski 2004: 55; Dobrowolski, Woźniak 1976), z drugiej zaś megalomania i bogata kultura symboliczna ( $\mathrm{z}$ mitem $\mathrm{w}$ roli organizatora), w ramach której funkcjonowały lokalne autorytety (Bystroń 1995). Wśród nich można wyróżnić przykład starców ${ }^{2}$. Oczywiście niemechanicznie, gdyż nie istniała uniwersalna reguła traktowania ich $\mathrm{z}$ szacunkiem ${ }^{3}$. Podobnie jak nie sposób wskazać bezwzględnie stałe cechy modelujące obraz obcego, w związku z którym będą w niniejszym tekście rozważane wybrane aspekty starości ${ }^{4}$.

„Starzy [pisał Jacek Oledzki - przyp. T.K.], jeśli nawet nie przedstawiają «wartości ekonomicznej», to tworzą coś więcej” (Olędzki 1991: 169). Honorowanie seniorów najłatwiej daje się zauważyć w społecznościach gerontokratycznych, choć i w tych o niegerontokratycznej strukturze bywali dowartościowywani (Ziółkowska-Kuflińska 2009: 129-133). Starczego magis, mając na uwadze zasugerowany w temacie kontekst ludowy, należałoby szukać w oralnym sposobie funkcjonowania społeczności wiejskiej i jej tradycyjnym (mitycznym) światopoglądzie. Nagromadzony wraz z wiekiem zasób wiedzy i doświadczeń czynił ze starców autorytety szczególnie silne i wybitnie konserwatywne. Sąsiadowali oni na wsi polskiej z przedstawicielami rzadkich profesji zaliczanymi do grupy obcych (By-

\footnotetext{
${ }^{2}$ Część rozważań i przykładów pochodzi z mej pracy doktorskiej Mityczni obcy. Dzieci $i$ starcy w polskiej kulturze ludowej XIX i poczatku XX wieku, Toruń 2012 (w maszynopisie). Praca została napisana pod kierunkiem dr hab. Violetty Wróblewskiej.

${ }^{3}$ Józef Burszta na przykład zwraca uwagę na niejednorodność społecznego położenia starców w poszczególnych zaborach na ziemiach polskich, wskazując przy tym różne rodzaje umów, które organizowały im życie, tzw. wymów i wycug (Burszta 1976: 444).

${ }^{4}$ Nawet jeśli występował na ziemiach polskich XIX i początku XX wieku katalog właściwości obcego, odpowiadający analizie Jana Stanisława Bystronia, to na ogół podlegał on relatywizacji na obszarze zamieszkiwanym przez konkretną grupę. Miały na to wpływ jej doświadczenia.
} 
stroń, Dynowski 1948: 36). Byli tyleż tutejszymi i zadomowionymi, ileż niezwykłymi, budzącymi niepokój obcymi. Osoba o statusie swojego obcego to, zdaniem Andrzeja Perzanowskiego, przykład odmieńca, postaci peryferyjnej i/lecz silnie oddziałującej na kulturę (Perzanowski 2009: 48). Zbudowana na podstawie opozycji bazowej swój - obcy tradycyjna kultura chłopska miała w starcach wyrazistych reprezentantów swojego dychotomicznego bytu. Koncentracja uwagi na nich odnosi się wprost do systemu kultury, którego byli częścią, ponieważ światem tradycyjnym kieruje metonimia (Burszta 2013: 204).

Obserwowana w polskiej kulturze ludowej mityczność generowała typ kultury w stanie „naturalnym”, niejako zastanym. W znacznym stopniu określał go przypisywany ludowi tradycjonalizm czy konserwatyzm (Myśliwski 2004: 56). Składały się na niego trzy elementy:

1) ujmowanie wsi jako wzoru bezczasowego, niezmiennego, skończonego;

2) ujmowanie samego siebie w roli członka tej grupy i tylko niej;

3) podporządkowanie się tej grupie, dające jednostce poczucie wartości i znaczenia" (Chałasiński 1984: 130-131).

W kulturze opartej na międzygeneracyjnym przekazie ustnym zwłaszcza osoby stare okazywały się depozytariuszami tradycji, „były żywą skarbnicą wiedzy wszelakiej” (Lehr 2007: 34). Starcy, dysponujący bogatą pamięcią biograficzną (wspomnieniowa), stanowili pamięć grupy. Uczestniczyli w procesie odtwarzania, przechowywania i przekazywania tradycji konstytuującej ludowy świat. Występowali w roli narratorów i/albo tłumaczy rzeczywistości (Stachowska 2009: 122). Ich słowa podtrzymywały kulturę, której główną motywacją istnienia było trwanie i przetrwanie (Myśliwski 2004: 56). W warunkach kultury tradycyjnej z silnym zapotrzebowaniem społecznym na pamięć (auto)biograficzną ${ }^{5}$, seniorzy mogli zajmować wysoką pozycję (Kościańczuk 2009: 140). Nobilitacja seniorów nie była jedynie upodobaniem „dawności”. Wiązała się z kon-

\footnotetext{
${ }^{5} \mathrm{Z}$ poglądem tym, mimo że rozpowszechnionym w nauce, nie zgadza się badający kultury oralne Jack Goody. Autor wykazuje daleko idącą ostrożność w przypisywaniu kulturom tradycyjnym narracyjnego zorientowania (Goody 2012: 31, 177, 198).

${ }^{6}$ Wiadomo, że „dawność” elementów kulturowych, ich pochodzenie z przeszłości, było na wsi powszechnie spotykanym uzasadnieniem wysokiego wartościowania (Tomicki 1981: 360). Przybierało ono formę autorytetu „,dawnych rzeczy” i „dawnych ludzi” - jeden
} 
kretnym doświadczeniem, a więc z tzw. życiową mądrością. W tym kontekście przekazana $\mathrm{w}$ folklorze słownym polskiej wsi funkcja strażnika pamięci ${ }^{7}$, pełniona przez starca i ceniona przez grupę, przedstawia się jako ogólniejsze świadectwo sposobu funkcjonowania kultury tradycyjnej. Konstatacja taka wymaga potraktowania tekstów literatury ustnej jako przystających, przynajmniej w pewnej mierze, do społeczno-kulturowej i historycznej rzeczywistości wsi polskiej (Lehr 2007: 117; Perzanowski 2009: 219-220).

Procesy wypierające rolę pamięci wspomnieniowej zdewaluowały znaczenie starców w kulturze współczesnej, zarówno polskiego miasta, jak i wsi. „Wielki starzec” musiał ustapić miejsca „,zrzędliwemu staruszkowi”, który nie ma nic pozytywnego do zaoferowania, gdyż starość to życiowa katastrofa (Wawrzyniak 2009: 20; Miszczak 2006: 306). W kulturze tradycyjnej wartościowanie fazy schyłkowej nie było tak jednoznaczne. Osoby i miejsca, które znajdowały się na peryferiach głównego nurtu życia, traktowano ambiwalentnie. Badania etnograficzne dotyczące sytuacji na wsi polskiej w wieku XIX i XX pokazują, że starcy spotykali się zazwyczaj ze społeczną dozą niechęci, a nawet agresji. „Kurp jest tak nieużyty [notowała wypowiedź informatora badaczka - przyp. T.K.], że często zrzuca z wozu rodzonych ojców swoich, chcących się z nim zabrać do kościoła, jeżeli ci nie zobowiążą się wynagrodzić zabrania odrobkiem lub ustępstwem z alimentu" (Mioduchowska 1958: 39). W opinii grupy starcy byli zbyt niedołężni, aby można było ich traktować jako pełnoprawnych członków społeczności; wymagali utrzymania i dodatkowej opieki, dlatego odnoszono się do nich nieprzychylnie. Konieczność zaprzestania uczestnictwa w zasiewach i zbiorach - czynnościach, wokół których koncentrowało się życie na wsi (Baniowska 2003: 127), zazwyczaj obniżała status społeczno-ekonomiczny polskich starców: „Czcij ojca, matkę i obchodź się z nimi do-

z respondentów Jacka Olędzkiego takim właśnie mianem zdefiniował samego siebie: „Stara może być dupa, a ja jestem dawny" (Olędzki 1991: 170).

${ }^{7}$ Taki aspekt starości często eksponują tzw. ludowe nowele, zwłaszcza wersje wątku „Trzy przestrogi”, w których umierający ojciec przekazuje swemu dorosłemu synowi ważne rady życiowe, a ich prawdziwość szybko znajduje potwierdzenie w codziennych sytuacjach. Tego typu wątki mające rodowód kaznodziejski w ludowym repertuarze znajdują niezwykle oryginalne rozwinięcie, odstające od oryginału, czyli od Historii rzymskich (Wróblewska 2007: 103). 
brze..., dopokąd ci gruntu nie zapiszą", przytaczał jako życiową dewizę polskich górali Władysław Orkan (1946: 125). Przekazanie gospodarstwa prowadziło wśród polskiego chłopstwa do utraty roli głowy rodziny, co skutkowało albo okazywaniem starcom lekceważenia, albo wygnaniem $\mathrm{z}$ domu.

Wydaje się [podsumowywał swoje obserwacje z ziemi dobrzyńskiej z przełomu XIX i XX wieku Jacek Olędzki - przyp. T.K.], że między wypędzaniem na żebry a niedopuszczeniem do uczestnictwa w sprawach gospodarstwa rodziców poważniejszej różnicy w kategoriach etycznych nie ma (Olędzki 1991: 278).

William Thomas i Florian Znaniecki już w latach 70. XX wieku zwracali uwage, że starcy, podobnie jak osoby niezamężne, nie uczestniczyli na równi z innymi w życiu wspólnoty (Thomas, Znaniecki 1976: 110, 114), co bywało oczywiście powodem spotykających ich trudności. Jednak towarzysząca im postawa nieprzychylnego zdziwienia, inspirując rozmaite w formie represje (na ogół towarzyskie i ekonomiczne), mogła także uruchamiać w grupie myślenie magiczne. Zachodziła paralela pomiędzy nieprzystosowaniem do określonych wymogów życia społeczno-gospodarczego (odbieganiem od przyjętej przez daną grupę normy) a uczestniczeniem w życiu zaświatów. Pobyt na społecznych obrzeżach pomagał w komunikowaniu się z sacrum. Funkcjonujący na marginesie ludowego świata wykluczeni starcy stawali się jednostkami niezwykłymi. Jako istoty graniczne otaczani byli względnym szacunkiem z obawy o ewentualną nadprzyrodzoną interwencję $w$ ich sprawie (dowodzi tego choćby figura starca jako wcielenia chodzącego po ziemi Jezusa). Tracąc cechy ludzkie i prawa społeczne, seniorzy przez graniczność swej pozycji zyskiwali inny, związany z sacrum autorytet, co przejawiało się m.in. w kulcie przodków, ceremoniach pogrzebowych czy rytach inicjacyjnych, w których starcy odgrywali główną rolę. Niedowidzące czy mówiące bełkotliwie osoby w społecznościach kultur archaicznych uchodziły za wyrocznie, którym przysługiwało prawo sądzenia, jak wierzono, bezstronnego, zdystansowanego od ludzkiej względności ${ }^{8}$. Antropologowie i etnografowie, stwierdza w swej książce

\footnotetext{
${ }^{8}$ Warto w tym miejscu przywołać pewne spostrzeżenia Zbigniewa Libery, dotyczące ludowej wizji świata, które czyni on, tropiąc znaczenie słuchu. Chłopskie uniwersum określa autor mianem „akustycznej pewności” (Libera 1995: 37). Starców, którzy mówią coraz mniej, należałoby umieścić w ciszy symbolizującej porządek nadprzyrodzony, ponieważ
} 
o ludziach starych Leon Dyczewski, ,zaobserwowali, że w społeczeństwach pierwotnych boskie przymioty łączono z wiekiem starszym. Bóstwa często wyobrażano jako stare, choć pełne siły i mądrości istoty wyższe" (Dyczewski 1994: 15-16) ${ }^{9}$. Jednocześnie staruszka i starzec budzili postawę rezerwy i/lub wrogości. Skoro zgodnie z tradycyjną taksonomią wierzono na przykład, że brak włosów jest oznaką przynależności do zaświatów, to borykające się z ich wypadaniem starsze osoby kwalifikowano do rangi istot demonicznych. Negatywny wizerunek starości mógł, jak sugeruje Urszula Lehr, utożsamiać sędziwe i samotne kobiety z czarownicami (Lehr 2007: 117; Burke 2009: 98-99).

O modelowaniu obrazu starca decydował system światopoglądowy grupy. Mógł on, nawet w podobnym kontekście sytuacyjnym, kształtować biegunowo odmienne wizerunki seniorów. Oskarżano ich więc o szkodliwe praktyki czarodziejskie. W pewnych sytuacjach spotkania z nimi uważano za niepomyślny zwiastun. Dlatego też unikano kontaktów ze starszymi osobami przed udaniem się w podróż czy na polowanie. Aspekt religijny z kolei czynił z nich „celebransów obrzędowych”, uruchamiając zachowania pozytywne, choć jednocześnie podszyte lękiem. W społecznościach o tradycyjnym światopoglądzie daje się zauważyć łączność przeciwstawnych postaw. Zjawisko to tłumaczone jest rozróżnieniem starości $\mathrm{z}$ jednej strony $\mathrm{w}$ sensie wieku, $\mathrm{z}$ drugiej zaś $\mathrm{w}$ znaczeniu procesu umierania. Niechęci do starca (jako jednostki ekonomicznie bezproduktywnej) mógł zarazem towarzyszyć szacunek powodowany lękiem z jego granicznego usytuowania w kulturze: „Niektóre ludy - pisała Urszula Lehr - nienawidząc swoich starców, traktowały ich dobrze z obawy przed zemstą duchów" (Lehr 2003: 74).

Postaci graniczne, do których obok dzieci, żebraków i obcych (etnicznie czy religijnie) zaliczyć można też starców, w myśleniu magicznym jawiły się jako skuteczni depozytariusze mocy. W razie konieczności, na przykład podczas klęsk elementarnych, grupa na swój pożytek aktywizo-

w myśl formuły „akustycznej pewności” wymaga się od sygnałów dźwiękowych swojej czasoprzestrzennej przynależności. Skoro poszczególnym dźwiękom odpowiadają określone fragmenty rzeczywistości, to logicznie brak dźwięków - ciszę i mających z nią związek starców przychodzi umieścić w rzeczywistości sacrum.

${ }^{9}$ Pewną społeczną pochodną tego gerontokratycznego ustosunkowania, realizującą się w wymiarze pragmatycznym, byłaby do dziś funkcjonująca instytucja starosty. 
wała moc poprzez złożenie ze starców ofiary. „W chwili, gdy decydowano się na ten akt, społeczność lokalna zrzucała $\mathrm{z}$ siebie cały bagaż kulturowy chrześcijaństwa" (Kolczyński 2000: 176), odkrywając tym samym pokłady mityczne, czy jak to określali częściowo respondenci badacza (ze wstydem i niedowierzaniem wspominający mordy na żebraku, staruszce i niemowlęciu, wpisane w nie tak odległe historie ich wsi) zabobonne czyny. W świetle tradycyjnego modelu światopoglądowego opatrywani znamieniem obcości byli obciążeni archetypem skazanego (Lehr 2003: 76). Wypierano ich już to $\mathrm{w}$ sferze świadomości, kiedy trafiali do szerokiego zbioru istot nieczystych, już to w praktykach eliminujących społecznie. Przykłady geograficznie odleglejsze, bo z terenów Azji, pokazują pozostawianie jednostek słabych samym sobie bądź zasądzanie wobec nich śmierci. Widmo klęski głodu, a więc bezpośrednia zależność od środowiska naturalnego, mogło być wystarczającym uzasadnieniem skazania: „kiedy zagrożona była egzystencja grupy, osoby stare i niedołężne [a więc niezdolne do zdobywania pożywienia - T.K.] opuszczały rodzinną osadę, by w samotności umrzeć" (Ziółkowska-Kuflińska 2009: 133). Według tradycyjnej koncepcji życia wydarzenie śmierci stanowiło warunek konieczny do dalszego biegu egzystencji. W związku z tym wypadki składania ofiar z ludzi, wśród których istotną grupą byli starcy, mogły mieć motywację kulturową ${ }^{10}$. Biorąc pod uwagę powyższe ustalenia, trudno jednoznacznie orzec, na ile obchodzenie się ze starcami na wsi, wspomniane przez informatorów Jarosława Kolczyńskiego, czy też obecne w utworach folkloru słownego $^{11}$, stanowiło dokładne odzwierciedlenie rzeczywistości, a na ile kreację ukazującą sposób myślenia grupy o własnej historii. Wydaje się mało prawdopodobne, aby dokonywane zabójstwa na seniorach poświadczały funkcjonowanie rytuału. Zdaniem Violetty Wróblewskiej, przekazy na ten temat odnotowane na polskiej wsi w XIX wieku stanowią raczej przejaw oddziaływania nauk kościelnych niż dowód występowania praktyk kultowych (Wróblewska 2007: 93, 96-97, 107, 120).

Przeobrażenia w kulturze śmierci znane $\mathrm{z}$ historii powszechnej (Tanaś 2008: 134-138) rzutowały na ewolucję w sposobie postrzegania starców,

\footnotetext{
${ }^{10}$ Przekonują o tym szerokie dane etnograficzne dotyczące tzw. społeczeństw plemiennych (cf. Szynkiewicz 1981; I. Kabzińska-Stawarz 1992).

${ }^{11}$ Cf. m.in.: Pawłowicz 1896; Gonet 1900; Łumiński 1900; Fedorowski 1903; Zborowski 1932.
} 
rozwijając bardzo różne modele ich traktowania: od czci wielkich mędrców do ageizmu - dyskryminacji ze względu na wiek (Stachowska 2009: 122; Zych 2010: 13-14; Nelson 2002). Procesy transformacyjne na wsi polskiej, dotyczące zarówno typu jej społecznej organizacji, jak i rodzaju światopoglądu, miały niewątpliwie znaczący wpływ na kształtowanie się wizerunku seniora. Modyfikujący się z retrospektywnego na perspektywiczny układ odniesienia zawierał zmianę stosunku ludzi do starości i śmierci. Dawną tradycję akceptacji odejścia zastapiło jego wycofanie posunięte aż do lęku przed samym imieniem śmierci (Ariès 1995: 41). Niegdyś, rzec można, podejmując myśl historyka i przenosząc ją na polskie ludowe realia, wspólnie z umieraniem (wkalkulowanym w codzienne życie) mieszkano i przez jego pryzmat ujmowano też postacie starców. Na śmierć patrzono bez przytłaczającego dramatyzmu: „ludzie - stwierdza autor chłopskiego pamiętnika - umierali bez trwogi i z nadzwyczajnym spokojem”, jak gdyby wybierali się w niedługą podróż, z której mieli nadzieję niebawem powrócić (Słomka 2008: 116). Narastający wobec śmierci lęk doprowadził - zdaniem Philippe'a Arièsa - do jej „zdziczenia” (Ariès 1992: 41-42). Skutkuje on m.in. wyraźnym ograniczeniem form jej społecznej obecności do działań podejmowanych przez wyspecjalizowane firmy usługowe. Dotyczy to sytuacji zarówno we współczesnych polskich miastach, jak i wsiach.

W kulturze ludowej oddziaływanie starców wykazywało analogię do procesów zaświadczonych $\mathrm{w}$ innych sytuacjach granicznych, znanych z antropologicznych analiz (Lehr 2007: 71). Kulturotwórczą aktywność starości wiązać należy z percepcją śmierci jako z jednej strony zjawiska zupełnie naturalnego, z drugiej zaś niezwykłego, wpisującego się w sacrum momentów nasilonej biologiczności (Wasilewski 2010: 163-164). Jeśli lęk przed śmiercią stanowił fundament kultur mitycznych (Cassirer 1998: 154), to także starcy na obszarze kultury ludowej (z jej mitycznym światopoglądem) spotykali się z różnie realizowanym zainteresowaniem grupy. Spowinowaceni ze śmiercią i zaświatami (jak mityczni herosi) podtrzymywali dwubiegunową rzeczywistość ludowego uniwersum w łączności. Następowała swoista amortyzacja, bo w świadomości społecznej władanie śmierci stawało się ograniczone - zagospodarowane przez człowieka, który ku niej zmierzał. Tym samym życie nabierało ca- 
łościowego sensu obezwładniającego horror vacui. W kulturze współczesnej śmierć skazana na różnorodne w swej formie wygnanie, pozbawiła starość wartości ${ }^{12}$. Seniorzy przestali być mitycznymi odmieńcami o statusie swój - obcy, stając się wielowymiarowo nieobecni (Beauvoir 2011) ${ }^{13}$.

\section{Literatura}

Ariès P., 1992, Człowiek i śmierć, przeł. E. Bąkowska, Warszawa.

Ariès P., 1995, Historia dzieciństwa. Dziecko $i$ rodzina $w$ dawnych czasach, przeł. M. Ochab, Gdańsk.

Baniowska E., 2003, „Chłopski świat” w świetle ksiag sqdowych wiejskich, w: Czas zmiany, czas trwania. Studia etnologiczne, red. J. Kowalska, S. Szynkiewicz, R. Tomicki, Warszawa, s. 117-132.

Beauvoir S., 2011, Starość, przeł. Z. Styszyńska, Warszawa.

Brzezińska A.W., 2009, Specjaliści od kultury ludowej?, „Nauka” nr 3, <http://www. pan.poznan.pl/nauki/N_309_09_Brzezinska.pdf>, 9.08.2013.

Burke P., 2009, Kultura ludowa we wczesnonowożytnej Europie, przeł. R. Pucek, M. Szczubiałka, Warszawa.

Burszta J., 1976, Społeczności lokalne, w: Etnografa Polski. Przemiany kultury ludo$w e j$, t. 1, red. M. Biernacka, Wrocław-Warszawa-Kraków, s. 437-475.

Burszta W.J., 2013, Kotwice pewności. Wojny kulturowe $z$ popnacjonalizmem $w$ tle, Warszawa.

Bylina S., 1999, Kultura ludowa Polski i Stowiańszczyzny średniowiecznej, Warszawa. Bylina S., 2002, Chrystianizacja wsi polskiej u schyłku średniowiecza, Warszawa. Bystroń J.S., 1995, Megalomania narodowa, Warszawa.

Bystroń J.S., Dynowski W., 1948, Kultura ludowa i ludoznawstwo w Polsce, Warszawa.

Cassirer E., 1998, Esej o człowieku. Wstęp do filozofii kultury, przeł. A. Staniewska, Warszawa.

12 Jednowymiarowość ujęcia jest oczywiście stereotypowa, ponieważ współcześnie, gdy negatywny obraz starości zdaje się dominować, można wyróżnić różne typy starości i typologie postaw wobec niej (Szatur-Jaworska 2000: 56-57).

${ }^{13} \mathrm{~W}$ tym kontekście społecznym fenomenem stał się w ostatnim czasie sofijski Dziadzio Dobry. Ten prawie stuletni, żyjący w opinii świętości starzec budzi uznanie zarówno wśród wierzących, jak i niewierzących współczesnych Bułgarów, od których pozyskuje ofiary na rzecz renowacji Cerkwi. Zainteresowanie nim jest na tyle duże, że powstają jego wizerunki, a fani założyli mu profil internetowy, cf. Nowaczewski 2013: 56-57. 
Chałasiński J., 1984, Młode pokolenie chłopów, t. 1, Warszawa.

Dobrowolski K., Woźniak A., 1976, Historyczne podtoże polskiej kultury chłopskiej, w: Etnografia Polski. Przemiany kultury ludowej, t. 1, red. M. Biernacka, Wrocław-Warszawa-Kraków, s. 59-90.

Dyczewski L., 1994, Ludzie starzy i starość w społeczeństwie i kulturze, Lublin.

Federowski M., 1903, Nieposzanowanie rodziców, w: Lud białoruski na Rusi Litewskiej. Materiaty do etnografii stowiańskiej zgromadzone w latach 1877-1905, t. 3, cz. 2, Tradycje historyczno-miejscowe oraz powieści obyczajowo-moralne, Kraków.

Gonet S., 1900, O babie co chciała chtopa utopić, w: Opowiadania ludowe. Z okolic Andrychowa, ,MAAE” t. 4, s. 227.

Goody J., 2012, Mit, rytuat i oralność, przeł. O. Kaczmarek, Warszawa.

Guzowski P., 2010, Starość kmieci polskich przełomu średniowiecza i czasów nowożytnych, „Kwartalnik Historii Kultury Materialnej” nr 1, s. 101-109.

Kabzińska-Stawarz I., 1992, Nic w przyrodzie nie ginie, „Etnografia Polska” z. 1, t. 36, s. $135-159$.

Kolczyński J., 2000, Ofiara z człowieka, „Etnografia Polska” z. 1-2, t. 44, s. 173-191.

Kościańczuk M., 2009, Starość - problem pamięci, w: Patrzqc na starość, red. H. Jakubowska, A. Raciniewska, Ł. Rogowski, Poznań, s. 137-146.

Lehr U., 2003, Oblicza starości, „Etnografia Polska” z. 1-2, t. 47, s. 71-102.

Lehr U., 2007, U schytku życia. Starość mieszkańców wsi Beskidu Ślqaskiego i Podhala, Warszawa.

Libera Z., 1995, Kto wszystko czuje, a nic nie gada, „Literatura Ludowa” nr 6, s. 31-40. Łumiński E., 1900, Na Huculszczyźnie (Garść wrażeń), „Ateneum” nr 2, s. 494-497.

Mioduchowska A., 1958, Wspótdziałanie gospodarcze w Brzozówce. W końcu wieku XIX $i$ w wieku XX, w: Studia i materiaty do historii kultury wsi polskiej $w$ XIX $i X X w$., red. K. Zawistowicz-Adamska, Wrocław, s. 25-73.

Miszczak E., 2006, Stereotypowy obraz cztowieka starego w Polsce, w: Starość i starzenie się jako doświadczenie jednostek i zbiorowości ludzkich, red. J.T. Kowalski, P. Szukalski, Łódź, s. 305-311.

Myśliwski W., 2004, Kres kultury chłopskiej, „Twórczość” nr 4, s. 53-61.

Nelson T.D. (red.), 2002, Ageism. Stereotyping and Prejudice against Older Persons, Cambridge-Massachusetts-London.

Nowaczewski A., 2013, Święty z sofijskiej ulicy, „Gość Niedzielny” 11 sierpnia, s. 5657.

Olędzki J., 1991, Murzynowo. Znaki istnienia i tożsamości kulturalnej mieszkańców wioski nadwiślańskiej XVIII-XX w., Warszawa.

Orkan W., 1946, Listy ze wsi i inne pisma społeczne. Wybór, Warszawa. 
Pawłowicz B., 1896, Kilka rysów z życia ludu w Zalasowej, „MAAE”, t. 1, s. 229-265.

Perzanowski A., 2009, Odmieńcy. Antropologiczne studium dewiacji, Warszawa.

Simonides D., 1988, Od kolebki aż do grobu. Ślaskie wierzenia, obrzędy $i$ zwyczaje rodzinne w XIX wieku, Opole.

Słomka J., 2008, Pamiętniki włościanina. Od pańszczyzny do dni dzisiejszych, Tarnobrzeg.

Stachowska I., 2009, Aksjologiczne aspekty starości, w: Patrzac na starość, red. H. Jakubowska, A. Raciniewska, Ł. Rogowski, Poznań, s. 115-125.

Staszczak Z. (red.), 1987, Stownik etnologiczny, Warszawa-Poznań.

Szatur-Jaworska B., 2000, Ludzie starzy i starość w polityce spotecznej, Warszawa.

Szynkiewicz S., 1981, Rodzina pasterska w Mongolii, Wrocław.

Tanaś S., 2008, Przestrzeń turystyczna cmentarzy. Wstęp do tanatoturystyki, Łódź.

Thomas W., Znaniecki F., 1976, Chłop polski w Europie i Ameryce, t. 1, przeł. M. Metelska, Warszawa.

Tomicki R., 1981, Kultura - Dziedzictwo - Tradycja, w: Etnografia Polski. Przemiany kultury ludowej, t. 2, red. M. Biernacka, M. Frankowska, W. Paprocka, WrocławWarszawa-Kraków, s. 353-369.

Wasilewski J.S., 2010, Tabu, Warszawa.

Wawrzyniak J., 2009, Oblicza starości, Łódź.

Wróblewska V., 2007, Ludowa bajka nowelistyczna (źródta - wątki - konwencje), Toruń.

Zadrożyńska-Barącz A., 1968, Fenomenologiczna koncepcja historii i kultury. Zastosowanie w polskich badaniach etnograficznych, „Etnografia Polska”, t. 12, s. 15-28.

Zborowski J., 1932, Drobne notatki z Podhala, Lwów, s. 9-10.

Ziółkowska-Kuflińska M., 2009, Antropologiczna mozaika starości w kulturach pozaeuropejskich, w: Patrzqc na starość, red. H. Jakubowska, A. Raciniewska, Ł. Rogowski, Poznań, s. 127-136.

Zych A., 2010, Dramat starzenia się a starość w dramacie, w: Starość i jej konsekwencje spoteczno-rodzinne. Materiaty z konferencji naukowej, red. S. Rogala, Opole, s. $11-18$. 
